\title{
Development of a Device for Continuous Monitoring Parameters of the Winding Structure of Textile Bobbins
}

\author{
Desarrollo de un dispositivo para el seguimiento \\ continuo de los parámetros de la estructura de bobinado \\ de las bobinas textiles
}

Mahammadali Nuraddin Nuriyev ${ }^{1} \bowtie$, Fazil Ali Veliyev² ${ }^{2}$ Hamid İnsaf Hamidov³, Rahib Aqagul Sailov ${ }^{4}$, Ilham Mahamad Seydaliyev ${ }^{5}$, Ganira Zargar Jabbarova ${ }^{6}$

\footnotetext{
${ }^{1}$ Azerbaijan State Economic University (UnEc), Baku, Azerbaijan

${ }^{2}$ Azerbaijan State Economic University (UNEc), Baku, Azerbaijan

${ }^{3}$ Azerbaijan State Economic University (UNEC), Baku, Azerbaijan

${ }^{4}$ Azerbaijan Kooperasiya University, Baku, Azerbaijan

${ }^{5}$ Azerbaijan State Economic University (UNEC), Baku, Azerbaijan

${ }^{6}$ Azerbaijan State Economic University (UNEC), Baku, Azerbaijan
}

Istiglaliyyat str., Baku, AZ1001, Azerbaijan. Email: mahammadali.nuriyev@unec.edu.az

Received on: August 15, 2017 Accepted on: November 30, 2017 Available online: January 1, 2018

How to cite this article: M. N. Nuriyev, F. A. Veliyev, H. I. Hamidov, R. A. Sailov, I. Mahamad-Seydaliyev, and G. Z. Jabbarova, "Development of a Device for Continuous Monitoring Parameters of the Winding Structure of Textile Bobbins", Ingeniería Solidaria, vol. 14, no. 24, pp. 10, Jan. 2018. doi: https://doi.org/10.16925/.v14i24.2183

\begin{abstract}
Introduction: The research "Improving the control methods for winding structure at friction drive machines" was conducted at Azerbaijan State Economic University in 2017.

Methods: To assess the efficiency of the proposed technique for processing signals, a model of a winding analyzer (wa) device, which allows the unwinding of the package, was designed and manufactured.

Results: The authors developed a methodology and a corresponding device to quantitatively assess the parameters of the winding structure by the light-section method.

Conclusions: The dimensions adopted while designing the device make it possible to exclude the influence of the non-roundness of the bobbin on the measurement results.

Originality: The equipment advancement and quality control improvement are the most urgent issues in textile industry. The quality requirements for package is constantly growing, while this research contributes to maintain it at a corresponding level, which ensures further development of textile industry as a whole.

Limitations: The research results can be practically implemented in new winding motion designs for spinning frames with cross-winding bobbin.
\end{abstract}

Keywords: Bundle structure, cross winding, packgage, textile bobbin, threader, winding mechanism. 


\title{
Desarrollo de un dispositivo para el seguimiento continuo de los parámetros de la estructura de bobinado de las bobinas textiles
}

\begin{abstract}
Resumen
Introducción: la investigación "Mejoramiento de los métodos de control para la estructura de bobinado en máquinas de fricción" se llevó a cabo en la Universidad Estatal de Economía de Azerbaiyán en el 2017.

Métodos: para evaluar la eficiencia de la técnica propuesta para el procesamiento de señales, se diseñó y se fabricó un modelo de dispositivo de análisis de bobinado (AB), el cual permite desenrollar el paquete. Resultados: los autores desarrollaron una metodología y el dispositivo correspondiente para realizar la evaluación cuantitativa de los parámetros de la estructura de bobinado mediante el método de sección luminosa.
\end{abstract}

Conclusiones: las dimensiones adoptadas al diseñar el dispositivo permiten excluir la influencia de la ausencia de redondez de la bobina en los resultados de la medición.

Originalidad: el avance del equipo y la mejora del control de calidad son los temas más urgentes en la industria textil. Los requisitos de calidad para el paquete están en constante crecimiento, en tanto que esta investigación contribuye a mantenerlo en el nivel correspondiente, lo cual garantiza un mayor desarrollo de la industria textil en su conjunto.

Limitaciones: los resultados de la investigación se pueden implementar de manera práctica en nuevos diseños de movimiento de enrollamiento para marcos giratorios con bobina de bobinado cruzado.

Palabras clave: estructura del fardo, bobinado cruzado, paquete, bobina textil, enhebrador, mecanismo de bobinado.

\section{Desenvolvimento de um dispositivo para o seguimento contínuo dos parâmetros da estrutura de enrolamento das bobinas têxteis}

\begin{abstract}
Resumo
Introdução: a pesquisa "Aperfeiçoamento dos métodos de controle para a estrutura de enrolamento em máquinas de fricção" foi realizada na Universidad Estatal de Economía de Azerbaiyán, em 2017.

Métodos: para avaliar a eficiência da técnica proposta para o processamento de sinais, foi desenhado e fabricado um modelo de dispositivo de análise de enrolamento, o qual permite 2, desenrolar a embalagem.

Resultados: os autores desenvolveram uma metodologia e o dispositivo correspondente para realizar a avaliação quantitativa dos parâmetros da estrutura de enrolamento mediante o método de seção luminosa.

Conclusões: as dimensões adotadas ao desenhar o dispositivo permitem excluir a influência da ausência de redondeza da bobina nos resultados da medição.

Originalidade: 0 avanço da equipe e a melhoria do controle de qualidade são os temas mais urgentes na indústria têxtil. Os requisitos de qualidade para a embalagem estão em constante crescimento, razão pela qual esta pesquisa contribui para mantê-lo no nível correspondente, o que garante maior desenvolvimento da indústria têxtil em seu conjunto.

Limitações: os resultados da pesquisa podem ser implementados de maneira prática em novos desenhos de movimento de enrolamento para molduras giratórias com bobina de enrolamento cruzado.
\end{abstract}

Palavras-chave: estrutura do fardo, enrolamento cruzado, embalagem, bobina têxtil, passa fio, mecanismo de enrolamento. 


\section{Introduction}

Improving the quality and competitiveness of the finished products of textile enterprises directly depends on the systematic and effective quality control of semi-finished products and raw materials at all the stages of textile production. One of the most significant stages of textile production is the formation of cross-wind bobbins. Crosswind bobbins are formed either on spineless spinning machines or by rewinding cobs on circular spinning machines.

The quality of cross-winding packages is determined by many parameters, including the density of the winding and its uniformity along the radius and generatrix, the form of the package and its deviation from the required form, the presence of structural defects in the form of compacted sections, bundle and tape winding, etc.

When forming bundle structures, the threads laid earlier act as a spreader by laying the thread that has violated the law dictated by the movement of the yarn feeder. At the same time, as the number of coils laid in the above-mentioned way increases, the forces that strive to return the coil to its normal position increases. As a result, the thread eventually slips out of the position determined by the bundle into a position determined by the yarn feeder. Since the lifting angle of the coil in the turnover area is zero, while the remaining area of the package acquires a non-zero value of $\beta$, there can be changes in the behavior of the yarn in these sections.

Based on calculations, it is possible to draw a conclusion about the relationship between the relief of the side surface of the package and the winding structure at a corresponding diameter. Indeed, in bundle structures, the packing of coils takes place in succession, while the height of the profile increases in the places of packing. Studies have shown that it is possible to determine the winding structure by the nature of the distribution of shadows in the lateral illumination of the package surface.

The aim of this work is to determine the basic parameters of the structure of the winding analyzer (WA): a device, which provides continuous monitoring of the structure parameters as the bobbin is unwound and the parameters are quantitatively assessed.

To achieve the aim of the research, the following tasks were set:
- Determine the mutual position of the photo-detector and illuminator in relation to the package surface, which eliminates the influence of the non-roundness of the bobbin on the analysis results of the winding structure.

- Establish the order of processing signals coming from the photo-detector, which allows to determine the presence of defects in the winding structure.

- Develop a structure of a winding analyzer (WA).

\section{Literature Review}

The parameters of the winding structure: the width of the layout, the lifting angle of a coil and the distance between the coils $\Delta$, depend on the structure of the winding mechanism. These parameters influence a number of technological properties of the package and its ability to process. In the stationary movement of the "winding shaft-bobbin" system, the kinematic relations between the number of moves performed by the yarn feeder and the number of turnovers of the bobbin at a distance of $\Delta=0$, are described in the works by Praček et al. [1], Liangxue [2] , Shams Nateri et al.[3].

In Rudovsky's work [4], the distance $\Delta \theta$ in the circumferential direction between subsequent coils is used to assess the winding structure. The distance $\Delta \theta$ is identified by the calculation method under conditions of a non-stationary movement of the "winding shaft-bobbin" system only with a transfer ratio of $i \approx 1$ between the bobbin and the winding shaft. Undoubtedly, this method cannot be used to assess the winding structure of the entire package.

In many cases, the above-mentioned parameters are determined by the kinematic relationships in the winding machine. Therefore, the analysis of these parameters is done with the calculation methods described by Rudovsky [4]. The work describes a technique for calculating the angular and linear distance between the coils according to the kinematic scheme of the winding mechanism, depending on the winding diameter. The linear distance between adjacent coils determines the defects, such as bundle winding, when adjacent coils are stacked on top of each other. One shortcoming of the described methodology is the lack of orientation regarding the use of computer technology, which makes it impossible to control the formation of bundle winding at all diameters. 
Jianhui et al. [5] describe a technique for analyzing the winding structure with the help of an electronic computer. For the analysis of the presence of bundle winding, two criteria are proposed: the fixation degree of the coil and the uneven distribution of the turnover points along the circumference of the bobbin.

Patent [6] proposes to modernize the $\mathrm{ABA}$ -3060 device for processing the measurement results on an electronic computer, which undoubtedly increases the efficiency of the measurement process. It should be noted that the described device has a significant drawback inherent in other similar structures as well. Due to the significant distance between the point of descent and the eyelet of the yarn feeder and its change during operation, it is unable to produce the actual curve of laying a coil upon turning over. The curve is often disturbed due to the fact that during the formation of a tourniquet, the tourniquet itself acts as a spreader by removing the thread from the position determined by the movement of the yarn feeder. The paper written by Trisch et al. [7] includes a description of a technique for recording the position of a yarn in the turnover section, which involves rolling the packages along the adhesive tape. Meanwhile, the yarn is pasted from the bobbin onto the tape in the position in which it was laid in the winding. It should be noted that while this technique can be used to analyze the disturbances of the soil position in the turnover area, it cannot be used to analyze the operation of the scattering mechanism due to the high cost of adhesive tapes, as Praček, Stanislav, Simončič, Barbara and Nace explain [8].

The latter method of control has a number of advantages. First of all, the primary data is obtained from the working elements and not from the thread as it is done when using the devices described by Ashhepkova [9]. Secondly, no errors are caused by the deformation of the thread and the difference in the movements of the yarn feeder and the descent point of the thread from the bobbin.

Unlike the analytical method described by Jianhui et al. [5], Jhatial et al. [10] and Rudowskij [4], when applying the above-mentioned measurement method, all factors affecting the winding structure, including those that were not considered in the calculations (the non-uniformity of slippage, the tension of the thread, the pressing force of the bobbin towards the windings shaft), are taken into account.
However, the described method can be used to assess the work of the winding mechanism and not the structure of the package. Besides, the uncontrolled deviations of the filament laying, caused by the profile of the package surface, cannot be assessed by this method [11].

The analysis shows that currently there are no calculation or experimental methods to analyze the structure of the entire winding area and to quantitatively assess the winding parameters. This work aims to create a new method and a corresponding device for its implementation.

When the package is illuminated by a beam of light directed tangentially towards the side surface of the package, the filament yarns produce shadows of the relief on the package surface. Recording the illumination of the surface in the section, commensurate with the dimensions of the filament, makes it possible to unequivocally identify the winding structure at any diameter while the package rotates. In order to automatically record the structure parameters, it is necessary to develop an algorithm for processing the signal from the photo-detector, which can be realized with the help of a special scheme. Figure 1 conditionally shows the shape of the signal coming from the photo-detector without taking into account the zero drift caused by the poor quality of the scheme used in the experiment.

Obviously, the first stage of processing should consist in allocating the pulses, the amplitude of which is greater than a certain level [12]. Besides, this level should be set up on the control panel of the wa device and may vary depending on the optical properties of the package.

After allocating the pulses, the amplitude of which is greater than the given one, you will get the diagram shown in Figure 1b. Obviously, the received pulses correspond to the constant frequency of the package rotation, the thickness of the filament and the height of the defects formed on the relief, which in turn determines the length of the shadow cast by the winding defect.

After selecting pulses, the duration of which is longer than the given one - Maag [13]; Nuriyev and Musayeva [14] - (the control duration should also be set up on the control panel of the device), it is possible to receive a sequence of pulses of standard length and amplitude as shown in Figure 1. This unequivocally presupposes the presence of a winding defect at the diameter under investigation. 
$u$

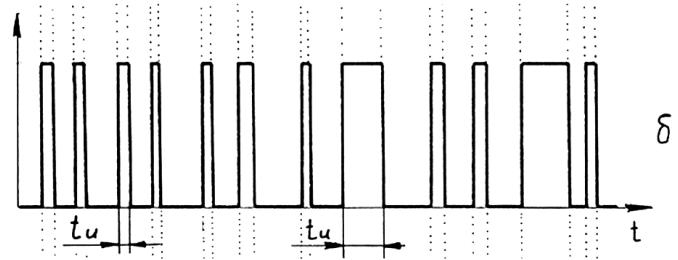

Figure 1a

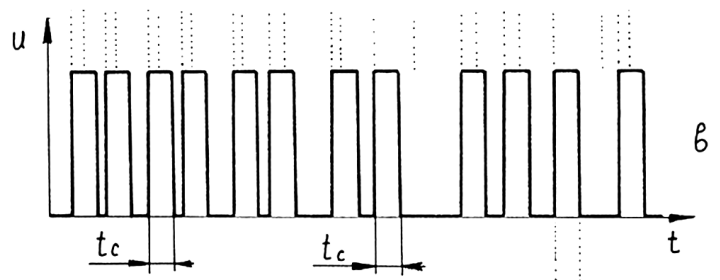

Figure 1b

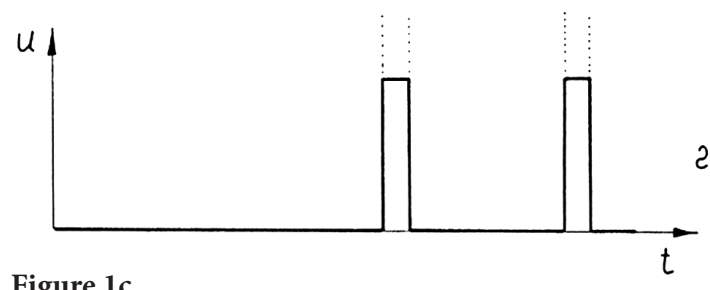

Figure 1c

Figure 1(a-c). Procedure for processing the pulses coming from the photo-detector.

Source: own work

In the process of the research, the thread is constantly unwound from the package, and its diameter decreases. Meanwhile, the defects of the structure are also unwound and the diameter at which no defects are observed gets closer. Obviously, by counting the number of pulses that succeed a certain number of turns of the package (Nuriyev and Imanova [15]); it is possible to quantitatively assess the quality of the package. When observing the entire package while it is unwound, it is possible to get an objective understanding of its quality.

\section{Methods}

To assess the efficiency of the proposed technique for processing signals, a model of a wA device, which allowed the unwinding of the package, was designed and manufactured. The scheme of the device is shown in Figure 2. It consists of an illuminator, which includes a lamp 1 and lenses 2 and 3 installed in a single body 4 . The body of the illuminator has a ledge, which is placed in a way that, by supporting the surface of the package 5 , the illuminator directs a light beam, always tangential to the surface of the bobbin. Above the contact point of the light beam and the bobbin surface, a photo-detector is installed. The photo-detector includes a focusing lens 6 and a photodiode 7 [16]. The bobbin receives the rotations of the electric motor at an angular frequency of $0.03 \mathrm{C}-1$.

The signal coming from the photo-detector is limited in amplitude to the processing unit 8 and can be fixed with the help of a high-speed recorder 9. The observations involved packages and their models, made of wood and pasted with white paper to ensure uniform optical properties of the surface. To identify the correspondence between the nature of the filament, the distribution and parameters of the signals, individual threads or groups of threads were glued onto such models. After this, the corresponding signal was recorded. The results of these tests revealed the presence of a significant influence of the non-roundness of the bobbin on the output signal of the device, which can lead to significant errors. To eliminate this phenomenon, it is necessary to place the light source in a certain way in relation to the bobbin.

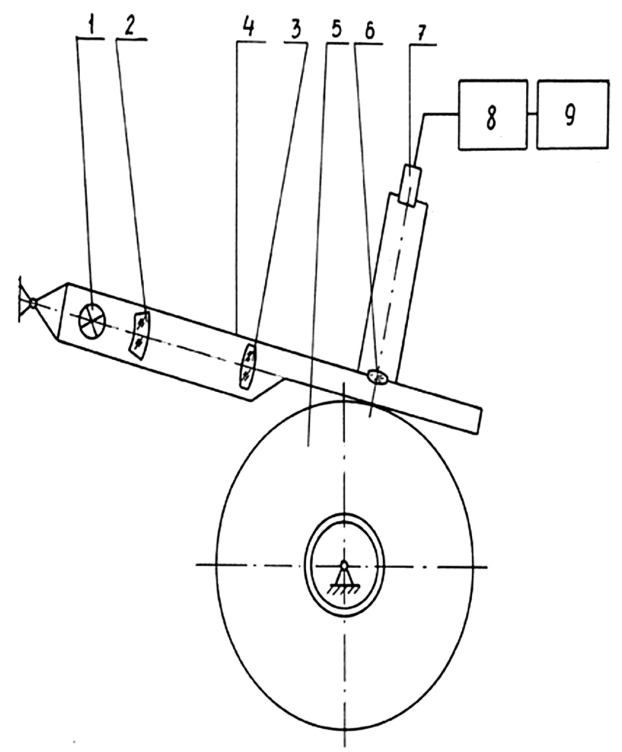

Figure 2. Scheme of the device for the continuous monitoring of the winding structure

Source: own work 


\section{Results}

Generally, the actual package of a cross-wind bobbin has a deviation from an ideally circular shape. Therefore, when the package is illuminated by light directed along its tangent to its lateral surface, and the photo-detector is placed above the contact point of the light beam and the surface, one can observe a blackout of the photo-detector caused by these deviations. Figure 3 a shows the registration process in the absence of non-roundness of the package, while Figure $3 \mathrm{~b}$ illustrates the process in case of roundness of the package.

Furthermore, the conditions under which the deviation from the round shape of the package will not significantly affect the signal coming from the photo-detector should be defined [4]. This is possible provided that any possible deviation from the round shape of the package does not form a shadow on the side surface of the package under illumination.

Suppose that there is a dent CBE (Figure 4a) in the form of a triangular groove on the surface of the package, it runs along the generatrix of the bobbin and has a vertex angle equal to $2 \varphi$.

The position of the light source and the photo-detector is determined by the coordinates shown in the same figure. When the bobbin rotates, the groove moves along its surface. If at the moment the groove passes under the photo-detector, the angle of inclination of the groove bottom to the horizontal $\varphi+\alpha$ is less than the angle of inclination of the light beam from the photo-detector passing through the same point, a shadow is formed on the bottom of the groove. This is recorded by the photo-detector.

The angle $\beta$ of inclination of the light beam (passing through point $\mathrm{C}$ of the intersection of
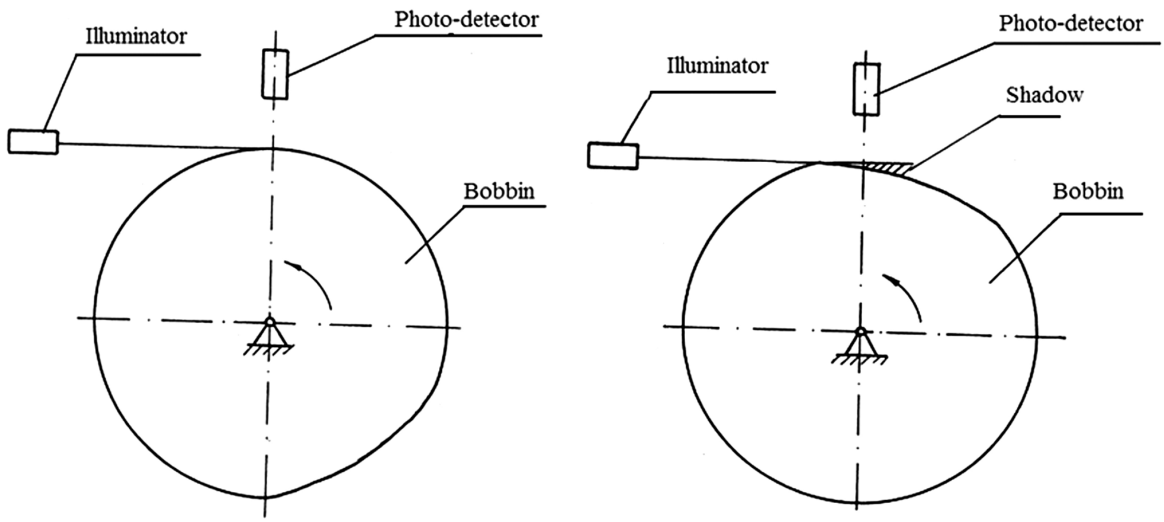

Figure 3. Scheme for the registration of the bobbin profile in the presence of non-roundness Source: own work
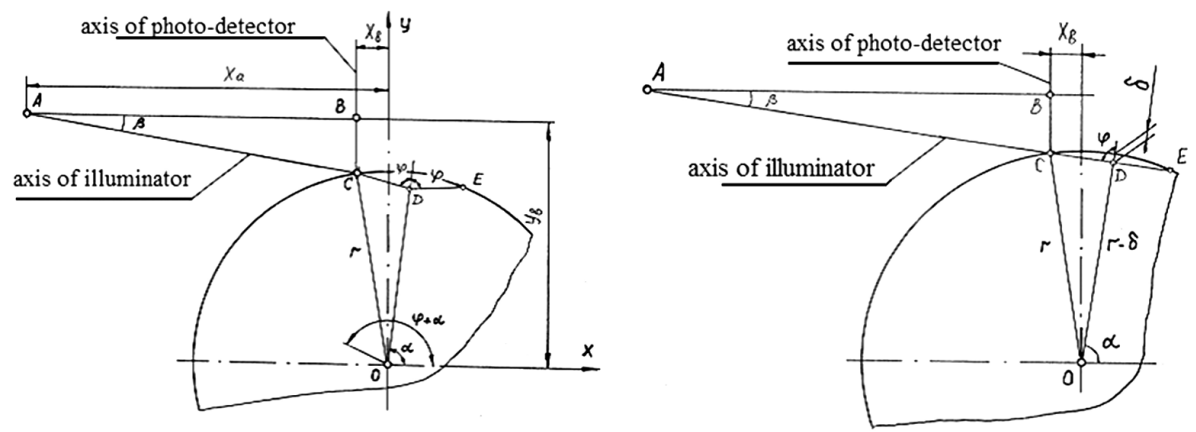

Figure 4. Determining the influence of non-roundness on the results of controlling the package profile. 
photodetector axis with the bobbin surface) to the horizontal can be determined from $\triangle \mathrm{ABC}$ by the following formula:

$$
\beta=\pi-\operatorname{arctg} \frac{A B}{B C},
$$

or excluding the function arctgx, which has a discontinuity at $\mathrm{x}=\frac{\pi}{x}$

$$
\beta=\pi-\arcsin \frac{A B}{\sqrt{A B^{2}+B C^{2}}} .
$$

To avoid the appearance of a shadow at the moment when the groove approaches point $\mathrm{C}$, the following condition must be met:

$$
\varphi+\alpha>\beta,
$$

or

$$
\varphi+\alpha>\pi-\arcsin \frac{A B}{\sqrt{A B^{2}+B C^{2}}} .
$$

As Figure 4 shows, $\mathrm{AB}=\mathrm{b}-\mathrm{c}$, while $\mathrm{BC}=\alpha-\sqrt{r^{2}-c^{2}}$

Substituting these expressions into (2), we eventually get

$$
\varphi+\alpha>\pi-\arcsin \frac{b-c}{\sqrt{(b-c)^{2}+\left(\alpha+\sqrt{r^{2}-c^{2}}\right)^{2}}}
$$

On the packages formed by the winding of the thread, we generally get

$$
\Phi \geq \frac{\pi}{2}
$$

In case of the equality $\Phi \geq \frac{\pi}{2}$, we get

$$
\alpha>\frac{\pi}{2} \arcsin \frac{b-c}{\sqrt{(b-c)^{2}+\left(\alpha+\sqrt{r^{2}-c^{2}}\right)^{2}}} .
$$

$\alpha$ needs to be expressed in terms of dimensions that determine the position of the photo-detector in relation to the center of the package. As can be seen in Figure $4 b$,

$$
\alpha=\frac{\pi}{2}+\arcsin \frac{c}{r}-\arccos \frac{r-\delta}{r},
$$

where $\delta$ is the non-roundness of the package surface.

Equating (4) and (5), we get an inequality for determining the coordinates of the photodetector.

$$
\frac{\pi}{2}+\arcsin \frac{c}{r}-\arccos \frac{r-\delta}{r}>\frac{\pi}{2} \cdot \frac{b-c}{\sqrt{(b-c)^{2}+\left(\alpha+\sqrt{r^{2}-c^{2}}\right)^{2}}},
$$

$\arccos \frac{r-\delta}{r}-\arcsin \frac{c}{r}<\arcsin \frac{b-c}{\sqrt{(b-c)^{2}+\left(\alpha+\sqrt{r^{2}-c^{2}}\right)^{2}}}$

The resulting inequality is transcendental and can cause significant difficulty for full analysis. However, taking into account the practical inaccuracy of the inequality, we can proceed as follows. Given the values of $\alpha, r, \delta$ and $c$, we can determine $\mathrm{b}$ in the extreme positions of the package, i.e. for $r_{\min }$ и $r_{\max }$.

In this case, we will need the value of the non-roundness of the package for further calculations. To determine the non-roundness of the package, a special device was designed and manufactured. The scheme of the device is shown in Figure 5. The device consists of a frame 1, on which the axis of the bobbin holder 2 and the watchlike indicator 3 with a flat support platform 4 are attached.

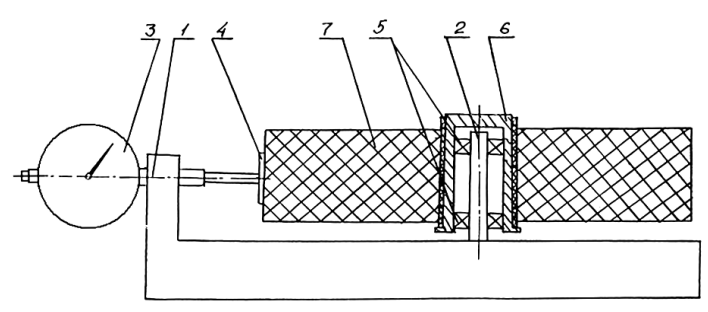

Figure 5. Scheme of the device for controlling the nonroundness of the packages Source: own work 
With the help of rolling bearings 2, the bobbin holder is placed on its own axis. The package 7 (produced on a spinning and twisting machine ПК-100М3) is installed on the bobbin holder touching the bobbin surface to the maximum diameter. After installation, the package is manually rotated to make a complete turn. At the same time, the maximum and minimum values of the indicator are recorded. In subsequent calculations, the difference $\delta$ between the maximum and minimum values is considered to be the non-roundness of the package. Table 1 shows the values of the measurements and their processing, according to [10], [17] and [18].

\section{Discussion}

The wa device was designed to analyze the entire complex of packages used in cotton spinning. It is required to check whether the ratio (4.6) is true for the packing of a ПК-100M3 machine under the proposed arrangement of the device.

Table 1. Values of the non-roundness of the packages

\begin{tabular}{|c|c|c|c|}
\hline Measurement № & $\delta, \mathrm{mm}$ & Measurement № & $\delta, \mathrm{mm}$ \\
\hline 1 & 0.90 & 17 & 0.95 \\
\hline 2 & 0.30 & 18 & 0.95 \\
\hline 3 & 0.99 & 19 & 0.63 \\
\hline 4 & 0.72 & 20 & 1.20 \\
\hline 5 & 0.58 & 21 & 1.73 \\
\hline 6 & 1.30 & 22 & 0.64 \\
\hline 7 & 1.56 & 23 & 0.70 \\
\hline 8 & 0.95 & 24 & 0.10 \\
\hline 9 & 0.58 & 25 & 0.94 \\
\hline 10 & 1.36 & 26 & 0.99 \\
\hline 11 & 1.35 & 27 & 0.92 \\
\hline 12 & 1.45 & 28 & 0.82 \\
\hline 13 & 1.30 & 29 & 0.27 \\
\hline 14 & 0.45 & 30 & 0.79 \\
\hline 15 & 0.85 & & \\
\hline 16 & 1.03 & average & 0.97 \\
\hline
\end{tabular}

Source: own work

The radius of the package varies from $r=22.5$ $\mathrm{mm}$ for an empty cartridge to $100 \mathrm{~mm}$ for a full package. At the same time, a varies from $57.5 \mathrm{~mm}$ to $135 \mathrm{~mm}$, as the device supports an invariable distance $\alpha-r$ from the surface of the package to the photo-detector. b and c are $210 \mathrm{~mm}$ and $2 \mathrm{~mm}$ respectively. According to the measurement results, the non-roundness of the bobbin $\delta$ is $0.97 \mathrm{~mm}$.

Substitution of these data provides the following results.

For $\mathrm{r}=22.5 \mathrm{~mm}$,

$\operatorname{arcos} \frac{22.5-0.97}{22.5}-\arcsin \frac{2}{22.5}<\arcsin \frac{210-2}{(210-2)+\left(57.5+\sqrt{22.5^{2}-2^{2}}\right)^{2}}$

$$
11^{\circ}-2,54^{\circ}<59^{\circ}
$$

For $\mathrm{r}=100 \mathrm{~mm}$, $\operatorname{arcos} \frac{100-0.97}{100}-\arcsin \frac{2}{100}<\arcsin \frac{210-2}{\sqrt{(210-2)^{2}+\left(135+\sqrt{100^{2}-2^{2}}\right)^{2}}}$

$7.96^{\circ}-1.14^{\circ}<41^{\circ}$

From results of the carried-out calculations it is visible that influence of non-roundness of a forging is absent.

Thus, the dimensions adopted while designing the device make it possible to exclude the influence of the non-roundness of the bobbin on the measurement results.

Thus, the sizes accepted at design of the device allow to exclude influence of not roundness of the reel on results of measurements. Besides, key parameters of a design of the device for continuous control of structure of winding are proved. Thereby the possibility of quantitative assessment of parameters of structure of winding is determined by a profile of a surface of a forging and the technique of her realization is developed.

In the course of carrying out researches mutual position of the photo detector and the lighter concerning a forging surface is defined. Such situation will exclude influence of non-roundness of the reel on results of the analysis of structure of winding. The offered order of processing signals from the photo detector allows to define existence of defects of structure of winding. 


\section{Conclusions}

The basic parameters of the device, designed for the continuous monitoring of the winding structure, have been theoretically substantiated. In addition to establishing the possibility of identification and quantitative assessment of the winding structure along the surface of the package, the author of the research has developed a corresponding implementation methodology.

The author of the research has determined the mutual position of the photo-detector and illuminator in relation to the package surface, which eliminates the influence of the non-roundness of the bobbin on the analysis results of the winding structure.

The basic parameters of the wA structure have been determined and a corresponding device was developed to quantitatively assess the parameters of the winding structure by the light-section method.

The proposed wa device eliminates the influence of the non-roundness of the bobbin and provides continuous control of the structure parameters during the winding process, as well as the quantitative assessment of the parameters.

The proposed wa device can be used to analyze the entire complex of packages used in cotton spinning.

\section{References}

[1] S. Praček, N. Pušnik, B. Simončič, and F. Tavčer Petra, "Model for Simulating Yarn Unwinding from Packages," Fibres and Textiles in Eastern Europe, vol. 23, no. 2(110), pp. 25-32, 2015. Available: http:// www.fibtex.lodz.pl/article1407.html

[2] L. Liangxue, Control System for Textile Winding Machine Convenient for Loading of Bobbin. IPC: B65H54/547, B65H63/00, B65H67/04, CN104386539 (A), 2015.

[3] A. Shams Nateri, F. Ebrahimi, and N. Sadeghzade, "Evaluation of Yarn Defects by Image Processing Technique," Optik - International Journal for Light and Electron Optics, vol. 125, no. 20, pp. 5998-6002, 2015. Available: https://www.infona.pl/resource/ bwmeta1.element.elsevier-007d0bde-22f9-3e47907f-01d858611d91

[4] P. N. Rudovsky, "Influence of Parameters of the Winding Mechanism on Laying Coils in Tourniquet
Formation," News of Higher Educational Institutions, Technology of Textile Industry, vol. 6, pp. 108-111, 1995.

[5] F. Jianhui, Y. Jaedeuk, K. Jeong-Suk, and J. Yoongho, "Real-Time Graphic Visualization of Filament Band Winding for Fiber-Reinforced Cylindrical Vessels," Journal of Composite Materials, vol. 50, no. 16, pp. 2165-2175, 2015. doi: https://doi. org/10.1177/0021998315602325

[6] Patent No. CN 201410607590. “Control System for Textile Winding Machine Convenient for Loading of Bobbin.” IPC: B65H54/547, B65H63/00, B65H67/04. Li L. - No. CN104386539 A, 2015.

[7] R. Trisch, E. Gorbenko, N. Dotsenko, and G. Kiporenko, "Development of Qualimetric Approaches to the Processes of Quality Management System at Enterprises According to International Standards of the ISo servis," Eastern-European Journal of Enterprise Technologies, vol. 4, no. 3(82), pp. 18-24, 2016. doi: https://doi.org/10.15587/1729-4061.2016.75503

[8] S. Praček, N. Pušnik, B. Simončič, and F. Tavčer Petra, "Model for Simulating Yarn Unwinding from Packages," Fibres and Textiles in Eastern Europe, vol. 23, no. 2(110), pp. 25-32, 2015. Available http:// www.fibtex.lodz.pl/article1407.html

[9] N. S. Ashhepkova, "Mathcad in the Kinematic and Dynamic Analysis of the Manipulator," Eastern-European Journal of Enterprise Technologies, vol. 5, no. 7(77), pp. 54-63, 2015. doi: https://doi. org/10.15587/1729-4061.2015.51105

[10] R. A. Jhatial, M. H. Peerzada, and U. Syed, "Optical Yarn Assessment System for Twist Measurement in Rotor-Spun Yarn," Mehran University Research Journal of Engineering and Technology, vol. 34, no. 1, pp. 25-32, 2016.

[11] Patent No. CN 201410607590. "Control System for Textile Winding Machine Convenient for Loading of Bobbin.” IPC: B65H54/547, B65H63/00, B65H67/04. Li L. - No. CN104386539 A, 2015.

[12] M. Nuriyev, I. Seydaliyev, I. Recebov, K. Dadashova, and T. Musayeva, "Determining the Dependences for Calculating a Conversion Scale of Profile Height of the Controlled Packing Surface. Nuriyev," Eastern-European Journal of Enterprise Technologies, vol. 2, no. 1(86), pp. 58-62, 2017.

[13] F. Maag, "Spinnspulen mit der Stufenpräzissionswicklung," Chemiefasern/Textilindustrie, vol. 6, pp. 416-420, 1985.

[14] M. N. Nuriyev and T. T. Musayeva, "Development of Algorithms Surface Recognition Forging Cross Winding," Bulletin of NTU "KhPI" Series: Mechanical-technological systems and complexes, vol. 49, no. 1221, pp. 52-55, 2016. 
[15] M. N. Nuriyev and G. M. Imanova, "Mechanical and Optical Methods and Means of Controlling Geometric Sizes and Shapes of Textile Packages," Bulletin of Science and Practice, vol. 5, no. 6, pp. 65-74, 2016.

[16] M. Nuriyev, K. Dadashova, I. Radzhabov, "Development of Methods for Recognition of Structural Defects Using Package Surface Image". ScienceRise, vol. 4, no. 2(21), pp. 6-10, 2016. doi: https://doi.org/ 10.15587/2313-8416.2016.66143. Available: http:// journals.uran.ua/sciencerise/article/view/66143
[17] M. N. Nuriyev, "Destructive Methods of Controlling the Density Distribution of the Winding Body," Progressive Technologies and Systems of Mechanical Engineering, vol. 4, no. 55, pp. 44-48, 2016.

[18] M. N. Nuriyev, F. A. Veliyev, “The Speed of Drying Cotton Components", in Proceedings of the Ninth International Conference on Eurasian Scientific Development, Vienna, May 20, 2016, pp. 112-115. 